\title{
Microstructure observations during the spring 2011 STRATIPHYT-II cruise in the northeast Atlantic
}

\author{
E. Jurado ${ }^{1, *}$, H. A. Dijkstra ${ }^{1}$, and H. J. van der Woerd ${ }^{2}$ \\ ${ }^{1}$ Institute for Marine and Atmospheric Research Utrecht (IMAU), Dept. of Physics and Astronomy, Utrecht University, \\ Utrecht, The Netherlands \\ ${ }^{2}$ Institute for Environmental Studies (IVM), VU University Amsterdam, Amsterdam, The Netherlands \\ *now at: Institute of Environmental Assessment and Water Research (IDAEA-CSIC), Jordi Girona 18-26, Barcelona 08034, \\ Spain
}

Correspondence to: E. Jurado (elena.jurado@idaea.csic.es)

Received: 12 March 2012 - Published in Ocean Sci. Discuss.: 11 June 2012

Revised: 8 October 2012 - Accepted: 11 October 2012 - Published: 7 November 2012

\begin{abstract}
Small-scale temperature and conductivity variations have been measured in the upper $100 \mathrm{~m}$ of the northeast Atlantic during the STRATIPHYT-II cruise (Las PalmasReykjavik, 6 April-3 May 2011). The measurements were done at midday and comprised 2 to 15 vertical profiles at each station. The derived turbulent quantities show a transition between weakly-stratified (mixed layer depth, MLD, $<100$ ) and well-mixed waters (MLD $>100)$, which was centered at about $48^{\circ} \mathrm{N}$. The temperature eddy diffusivities, $K_{T}$, range from $10^{-5}$ to $10^{0} \mathrm{~m}^{2} \mathrm{~s}^{-1}$ in the weakly-stratified stations, and range from $3 \times 10^{-4}$ to $2 \times 10^{0} \mathrm{~m}^{2} \mathrm{~s}^{-1}$ in the well-mixed stations. The turbulent kinetic energy dissipation rates, $\varepsilon$, range from $3 \times 10^{-8}$ to $2 \times 10^{-6} \mathrm{~m}^{2} \mathrm{~s}^{-3}$ south of the transition zone, and from $10^{-7}$ to $10^{-5} \mathrm{~m}^{2} \mathrm{~s}^{-3}$ north of the transition zone. The station-averaged $K_{T}$ values throughout the mixed layer increase exponentially with the wind speed. The stationaveraged $\varepsilon$ values throughout the mixed layer scale with the wind stress similarity variable with a scaling factor of about 1.8 in the wind-dominated stations $\left(\varepsilon \approx 1.8 u_{*}^{3} /(-\kappa z)\right)$. The values of $K_{T}$ and $\varepsilon$ are on average 10 times higher compared to the values measured at the same stations in July 2009. The results presented here constitute a unique data set giving large spatial coverage of upper ocean spring turbulence quantities.
\end{abstract}

\section{Introduction}

Observations as well as results from climate models indicate a strengthening of the vertical stratification in the midlatitude oceans due to global warming (Sarmiento et al., 1998; Levitus et al., 2000; Toggweiler and Russell, 2008). Changes in vertical stratification patterns determine the proximity of phytoplankton to light and nutrients and therefore influence the capacity for primary production (Behrenfeld et al., 2006). The link between stratification and phytoplankton dynamics is, however, not fully understood, mainly due to the technical limitations on obtaining adequate field and laboratory data.

Turbulence at the smallest scales, i.e. in the energy dissipation range, is a key player in the link between stratification and phytoplankton (Huisman and Sommeijer, 2002). These small-scale motions are commonly determined with so-called microstructure profilers (low-inertia free-falling instruments) which measure temperature and/or the shear velocity profiles with a very high spatial resolution (Gregg and Cox, 1971). From these measurements, one can derive the temperature eddy diffusivity $K_{T}$, the temperature variance dissipation rate $\chi_{T}$, and the turbulent kinetic energy (TKE) dissipation rate $\varepsilon$. The majority of the reported microprofiler surveys have been carried out in localized regions (Lombardo and Gregg, 1989; Sharples et al., 2001), with very few exceptions covering a long oceanic transect (Lozovatsky et al., 2005; Mouriño-Carballido et al., 2011). Measured values of $K_{T}$ range from $10^{-2} \mathrm{~m}^{2} \mathrm{~s}^{-1}$ in the mixed layer to 
$10^{-5} \mathrm{~m}^{2} \mathrm{~s}^{-1}$ in the deep ocean away from boundaries (Ferrari and Polzin, 2005). Values of $\varepsilon$ are more uniform in depth and generally range from $10^{-8} \mathrm{~m}^{2} \mathrm{~s}^{-3}$ to $10^{-6} \mathrm{~m}^{2} \mathrm{~s}^{-3}$. The magnitude of $K_{T}$ in the oceanic mixed layer is proportional to the depth of the mixed layer (MLD) (Large et al., 1994). The vertical structure of $\varepsilon$ in the oceanic mixed layer can be correlated to the atmospheric forcing (e.g. surface buoyancy flux, wind stress), but empirically determined scaling factors in the open ocean are scarce (Oakey and Elliott, 1982; Anis, 2006).

To understand the link between stratification changes through turbulence and phytoplankton changes, the interaction of physical, chemical and biological processes is extremely important. Yet, integrated, multidisciplinary studies covering these aspects are scarce. Such an approach has been followed by the STRATIPHYT research program (http: //projects.nioz.nl/stratiphyt), in which simultaneous comprehensive measurements of small-scale turbulent mixing, phytoplankton, photosynthetic active radiation, and nutrient distributions were carried out in the upper northeast Atlantic ocean. The northeast Atlantic Ocean offers a clear northsouth change in stratification, with permanent stratification in the subtropics and seasonal stratification in the temperate zones. The thermal structure and mixing in the northeast Atlantic is relatively uninfluenced by mesoscale eddy activity and horizontal advection (e.g. compared to the Gulf Stream region in the western Atlantic (Ezer, 2000)), allowing better assessment of the relation between atmospheric forcing and turbulence quantities. The sampling strategy of the cruises STRATIPHYT-I (Las Palmas-Reykjavik, 15 July-9 August 2009) and STRATIPHYT-II (Las PalmasReykjavik, 6 April-3 May 2011) is unique due to its nearlysynoptic measurements with large latitudinal coverage in the Atlantic. The drawback of the following sampling strategy is the limited number of profiles in each station, which makes it difficult to obtain robust turbulence quantities, but gives some insight into the latitudinal change of turbulence in the upper layer of the ocean.

The upper ocean turbulence properties from the STRATIPHYT-I cruise have been discussed in detail in Jurado et al. (2012), hereinafter indicated by JDW12. In the summer of 2009 , the upper ocean was stably stratified at all stations with mixed layer depths ranging from $20 \mathrm{~m}$ to $45 \mathrm{~m}$ (JDW12). The temperature eddy diffusivities $K_{T}$ and the TKE dissipation rates $\varepsilon$ showed relatively low values (e.g. $\left\langle K_{T}\right\rangle$ : from $10^{-6}$ to $10^{-1} \mathrm{~m}^{2} \mathrm{~s}^{-1},\langle\varepsilon\rangle$ : from $5 \times 10^{-9}$ to $\left.10^{-6} \mathrm{~m}^{2} \mathrm{~s}^{-3}\right)$ characteristic of midday summer measurements. The column- and station-averaged $K_{T}$ values in the mixed layer were positively correlated with the surface wind speed. At the wind-dominated stations, the values of $\varepsilon$ were found to scale well with the wind-stress similarity variable, with a scaling factor of 0.2 (JDW12).

The STRATIPHYT-II cruise has provided an opportunity to extend the results obtained in STRATIPHYT-I by applying the same strategy of sampling to a different season. In spring, higher levels of turbulence in the upper ocean are expected due to earlier convective and strong wind mixing events during winter (Whalen et al., 2012), and there is also the possibility of a (spring) phytoplankton bloom. The primary objective of the present work is to provide a detailed description of the vertical small-scale turbulent mixing properties measured in the STRATIPHYT-II cruise. This description is aimed toward the relevant information that can be related, in subsequent studies, to the measured phytoplankton distributions, and we focus on the vertical and the inter-station changes of $K_{T}$ and $\varepsilon$. The relation of the turbulence quantities to the phytoplankton distributions is not assessed in the present work because it is not straightforward, as mixing can both retard and accelerate phytoplankton sinking (Ross, 2006), and because it would require the analysis of additional environmental factors.

In Sect. 2 we present the cruise data, and in Sect. 3 we present the methodology to derive the turbulence quantities $K_{T}$ and $\varepsilon$. Results on the latitudinal variation of $K_{T}$ and $\varepsilon$ are provided in Sect. 4 together with an analysis of the relation between $\varepsilon$ and the atmospheric forcing, and a comparison with the results of the STRATIPHYT-I cruise. A summary and discussion of the results, together with the main conclusions are provided in Sect. 5. Additional details are included in the Appendix and in the Supplement.

\section{Cruise data}

\subsection{Sampling details}

During the STRATIPHYT-II cruise on board the RV Pelagia (6 April 2011: Las Palmas de Gran Canaria $\left(28^{\circ} \mathrm{N}, 15^{\circ} \mathrm{W}\right)$ - 3 May 2011: Reykjavik $\left(64^{\circ} \mathrm{N}, 22^{\circ} \mathrm{W}\right)$ ), we used a commercial microstructure profiler (Self Contained Autonomous Microstructure Profiler, SCAMP, manufactured by Precision Measurement Electronics (PME), see http://www.pme.com) to measure turbulence-scale temperature and conductivity profiles in the upper $100 \mathrm{~m}$ of the ocean.

The SCAMP is a battery-powered free-fall profiler designed to collect data down to $100 \mathrm{~m}$ depth at a sampling rate of $100 \mathrm{~Hz}$. The $0.76 \mathrm{~m}$ long profiler (diameter $0.07 \mathrm{~m}$, mass $6 \mathrm{~kg}$ ) was equipped with two fast response temperature sensors, a fast conductivity sensor, an accurate conductivity and temperature sensor, and a pressure sensor. The accuracy of the fast and precision thermistors are $0.05^{\circ} \mathrm{C}$ and $0.02{ }^{\circ} \mathrm{C}$, respectively. The accuracy characteristics of the conductivity pair are $0.45 \mathrm{~S} \mathrm{~m}^{-1}$ and $0.02 \mathrm{~S} \mathrm{~m}^{-1}$, and for the pressure sensor, $0.5 \%$ of the full scale range. SCAMPs have been used in a number of field studies, most of them in coastal or limnological areas (see http://www.pme.com/ HTMLDocs/Library_Scamp.html for a detailed record).

The SCAMP was deployed continuously from $\sim 11 \mathrm{~h}$ to $\sim 15 \mathrm{~h}$, with each vertical cast taking around $20 \mathrm{~min}$. The 4-h daily sampling resulted in 2 to 15 casts at each station; 
Table 1. Information of the CTD stations where SCAMP measurements were performed during the STRATIPHYT-II cruise.

\begin{tabular}{|c|c|c|c|c|c|}
\hline Station & Location & Date & $\begin{array}{l}\text { Profiling }^{\mathrm{a}} \\
\text { start time }\end{array}$ & $\begin{array}{l}\text { Number } \\
\text { of profiles }\end{array}$ & $\begin{array}{c}\text { Travelled }^{\mathrm{b}} \\
\text { distance }[\mathrm{nm}]\end{array}$ \\
\hline 0 & $29.0^{\circ} \mathrm{N}, 15.0^{\circ} \mathrm{W}$ & 8 Apr 2011 & $11: 42 \mathrm{~h}$ & 10 & 0 \\
\hline 1 & $30.0^{\circ} \mathrm{N}, 15.1^{\circ} \mathrm{W}$ & 9 Apr 2011 & $11: 42 \mathrm{~h}$ & 11 & 50 \\
\hline $2 a$ & $31.2^{\circ} \mathrm{N}, 14.9^{\circ} \mathrm{W}$ & 10 Apr 2011 & $11: 21 \mathrm{~h}$ & 5 & 100 \\
\hline $2 b$ & $31.2^{\circ} \mathrm{N}, 14.9^{\circ} \mathrm{W}$ & 11 Apr 2011 & $10: 36 \mathrm{~h}$ & 5 & 100 \\
\hline 3 & $32.8^{\circ} \mathrm{N}, 14.6^{\circ} \mathrm{W}$ & 12 Apr 2011 & $11: 15 \mathrm{~h}$ & 13 & 150 \\
\hline 5 & $34.7^{\circ} \mathrm{N}, 14.3^{\circ} \mathrm{W}$ & 13 Apr 2011 & $11: 07 \mathrm{~h}$ & 15 & 250 \\
\hline 7 & $36.5^{\circ} \mathrm{N}, 13.9^{\circ} \mathrm{W}$ & 15 Apr 2011 & $10: 16 \mathrm{~h}$ & 14 & 350 \\
\hline 9 & $38.4^{\circ} \mathrm{N}, 13.6^{\circ} \mathrm{W}$ & 16 Apr 2011 & $11: 06 \mathrm{~h}$ & 11 & 450 \\
\hline 11 & $40.5^{\circ} \mathrm{N}, 13.2^{\circ} \mathrm{W}$ & 18 Apr 2011 & $11.09 \mathrm{~h}$ & 14 & 550 \\
\hline 13 & $42.3^{\circ} \mathrm{N}, 12.9^{\circ} \mathrm{W}$ & 19 Apr 2011 & $11: 17 \mathrm{~h}$ & 11 & 650 \\
\hline 15 & $44.3^{\circ} \mathrm{N}, 12.6^{\circ} \mathrm{W}$ & 20 Apr 2011 & $10: 10 \mathrm{~h}$ & 11 & 750 \\
\hline 17 & $45.5^{\circ} \mathrm{N}, 12.4^{\circ} \mathrm{W}$ & 21 Apr 2011 & $11: 10 \mathrm{~h}$ & 14 & 850 \\
\hline 22 & $52.6^{\circ} \mathrm{N}, 16.5^{\circ} \mathrm{W}$ & 24 Apr 2011 & $11: 04 \mathrm{~h}$ & 13 & 1100 \\
\hline 23 & $54.6^{\circ} \mathrm{N}, 16.5^{\circ} \mathrm{W}$ & 25 Apr 2011 & $8: 28 \mathrm{~h}$ & 2 & 1150 \\
\hline 25 & $58.0^{\circ} \mathrm{N}, 16.5^{\circ} \mathrm{W}$ & 28 Apr 2011 & $11: 34 \mathrm{~h}$ & 9 & 1250 \\
\hline 27 & $59.5^{\circ} \mathrm{N}, 18.0^{\circ} \mathrm{W}$ & 29 Apr 2011 & $10: 56 \mathrm{~h}$ & 14 & 1350 \\
\hline 29 & $60.7^{\circ} \mathrm{N}, 19.3^{\circ} \mathrm{W}$ & 30 Apr 2011 & $11: 01 \mathrm{~h}$ & 13 & 1450 \\
\hline 30 & $61.7^{\circ} \mathrm{N}, 20.5^{\circ} \mathrm{W}$ & 1 May 2011 & $11: 01 \mathrm{~h}$ & 11 & 1500 \\
\hline 32 & $62.8^{\circ} \mathrm{N}, 21.7^{\circ} \mathrm{W}$ & 2 May 2011 & $10: 43 \mathrm{~h}$ & 11 & 1600 \\
\hline
\end{tabular}

the number of casts was constrained by adverse hydrodynamic conditions and the tendency of the microprofiler to drift away from the ship. In total, we obtained 207 SCAMP casts at 18 CTD stations (Fig. 1, Table 1). The profiler was ballasted with floats to maintain a stable vertical orientation and a nominal descent rate of $10 \mathrm{~cm} \mathrm{~s}^{-1}$. The data was recorded internally and downloaded after each recovery. The SCAMP's slow fall speed allowed it to collect data at a high vertical resolution, which is needed to characterize the smallscale turbulent motions.

\subsection{Microstructure data processing}

The microstructure data processing is only briefly described here. If required, the beginning and end of the temperatureconductivity-pressure profiles were rejected to avoid spectra contaminated by variations of the profiler descent rate. The profiles were further sharpened and smoothed, and secondorder Butterworth Brick-Wall filtered, using a recursive filter technique as described in Fozdar et al. (1985). Depth-binning was conducted in segments of $1 \mathrm{~m}$ ( $\sim 700$ scans $)$. The $1-\mathrm{m}$ scale was chosen as a suitable trade-off between the need of high vertical resolution and the need of statistical robustness. More details on the averaging procedure applied in the depthbinning are presented in Appendix A.

The salinity was derived from the trimmed-smoothedsharpened-filtered and depth-binned conductivity and temperature profiles. The density was computed using the UN-
ESCO (1981) equation of state for sea water, using salinity and temperature data. The depth was derived from the pressure sensor by knowing the density of the surrounding water. The molecular kinematic viscosity, $v\left(\mathrm{~m}^{2} \mathrm{~s}^{-1}\right)$, which is weakly dependent on salinity and pressure but strongly dependent on temperature, was computed from the polynomial approximation reported in ISW-SST (1999 tool box). The values of the vertical gradient of the temperature fluctuations, $\widehat{\partial T^{\prime} / \partial z}$ (the indicating a trimmed-sharpened-smoothedfiltered quantity, $T$ the temperature, and $z$ the vertical coordinate), were derived from the time-based derivative of the temperature fluctuations, $\widehat{\partial T^{\prime} / \partial t}$, divided by the fall speed of the microstructure profiler, $\widehat{v_{\text {instr }}}$. $\widehat{\partial T^{\prime} / \partial t}$ was obtained from the de-trended (with respect to the temporal mean) time-based derivatives of the temperature. $\widehat{v_{\text {instr }}}$ was obtained from the linear least squares differentiation of the scan-based depth signal (fitting windows of 50 scans around each scan), multiplied by the sample rate of the instrument $(100 \mathrm{~Hz})$.

The fall velocity of the SCAMP, $v_{\text {instr }}$, must satisfy the applicability of Taylor's (1938) hypothesis of "frozen turbulence" in order to convert time records into vertical profiles. This assumption, common in turbulence microstructure studies (Soloviev et al., 1988; Jonas et al., 2003), was verified by comparing the estimated turbulence velocities with the probe velocity (in the order of $0.1 \mathrm{~ms}^{-1}$ ). The turbulence velocity scales as $u \sim(\varepsilon L)^{1 / 3}$, where $L$ is the root mean square of the length scale of the overturning eddies. Using the values of the centered length scale $L_{C}$ (Imberger and Boashash, 1986), $L$ 


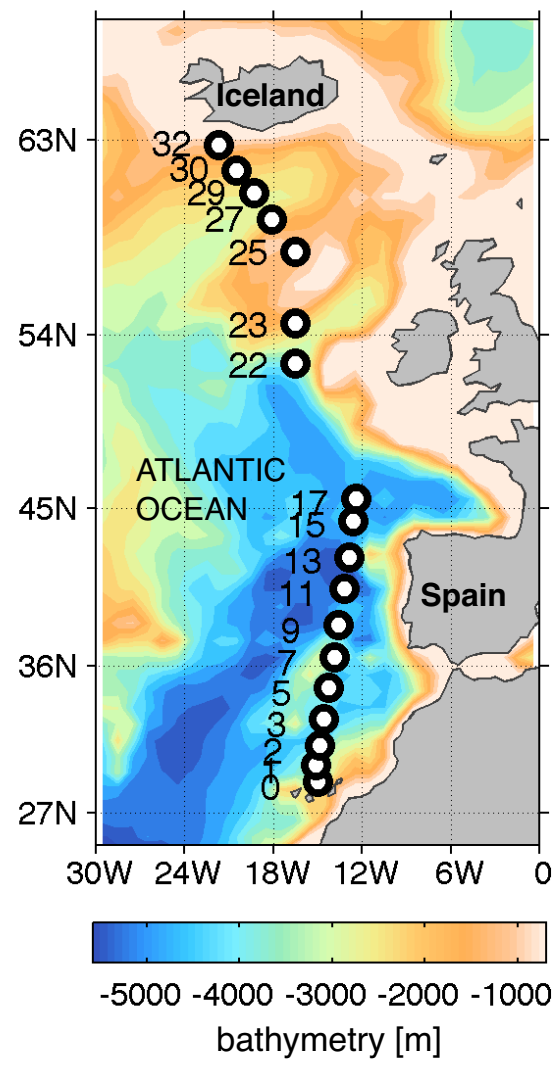

Fig. 1. Map with the location of the CTD stations where SCAMP measurements were performed during the STRATIPHYT-II cruise (6 April-3 May 2011). The details of each depicted station are presented in the accompanying Table 1 .

was found to have a maximum value of $\sim 10 \mathrm{~m}$ (Fig. SM1 in the Supplement). The maximum value of the TKE dissipation rate $\varepsilon$ was found equal to $2 \times 10^{-5} \mathrm{~m}^{2} \mathrm{~s}^{-3}$ (Sect. 4.2). The turbulence velocity, $u$, resulted in a maximum value of $0.06 \mathrm{~m} \mathrm{~s}^{-1}$, which was lower than the probe free-fall velocity. Therefore, Taylor's (1938) hypothesis was used for all data segments measured by the microprofiler.

\subsection{Meteorological data}

The onboard meteorological station measured air temperature, humidity, wind speed and direction, downward shortwave radiation flux, and air pressure. The data was sampled every minute and stored as averages over the time of each SCAMP cast. A malfunction of the anemometer occurred at the stations 0,1 , and $2 a$. The cloud cover percentage and wave height were estimated from observations made every $3 \mathrm{~h}$, and the rainfall rate was estimated $2 \mathrm{mmh}^{-1}$ during the rainy days (stations 15 and 27).

Together with the sea surface temperatures and the sea surface salinity derived from the extrapolation to the surface from those measured by the microstructure profiler, the meteorological data were used to compute the net surface (a)

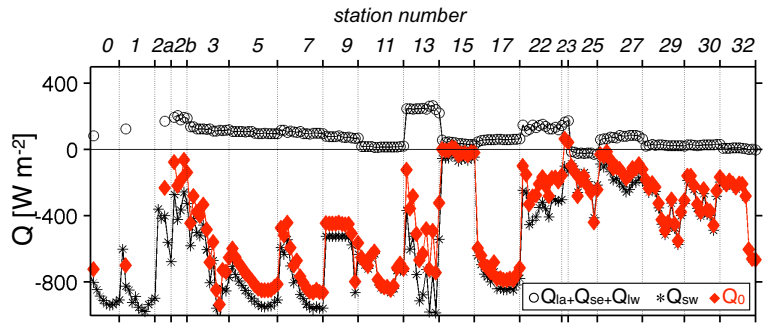

(b)

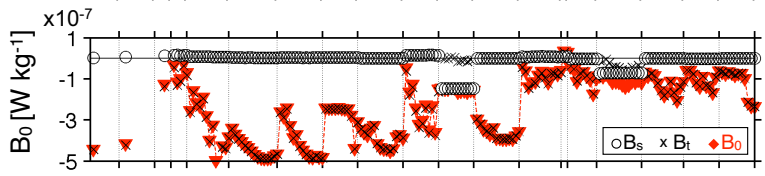

(c)

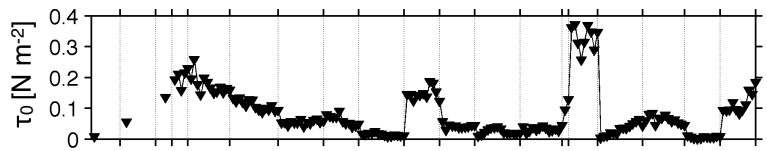

(d)

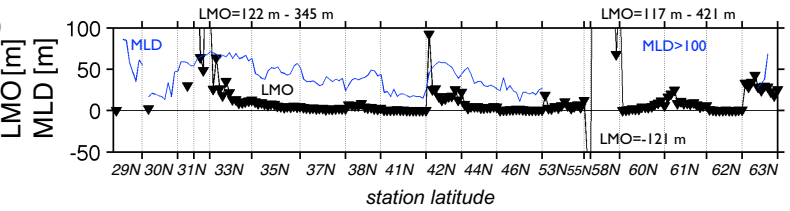

Fig. 2. Meteorological data averaged over the time of each SCAMP profile: (a) net surface heat flux $Q_{0}$ and related components (latent heat flux $Q_{\text {la }}$, sensible heat flux $Q_{\text {se }}$, net long-wave heat flux $Q_{l w}$, short-wave radiation flux $Q_{\mathrm{sw}}$ ); (b) net surface buoyancy flux $B_{0}$ and related components (thermal surface buoyancy flux $B_{\mathrm{t}}$, haline surface buoyancy flux $B_{\mathrm{S}}$ ); (c) surface wind stress $\tau_{0}$; (d) MoninObukhov length (LMO), and mixed layer depth (MLD). $Q_{0}$ is defined positive upward and hence for $B_{0}<0$ the buoyancy flux is stabilizing. Each marker represents a profile, and each dotted vertical line indicates the last profile of each sampling station. The number of the corresponding station is shown at the top of the figure. A malfunction of the anemometer occurred at the stations 0,1 , and $2 a$, resulting in a lack of the derived $\tau_{0}$ and LMO. Stations 22 to 30 had MLDs deeper than $250 \mathrm{~m}$. The MLDs depicted for the stations $0,1,11,17$, and 32 have to be treated with caution because they were not clearly defined from the temperature profiles.

heat flux $Q_{0}\left(\mathrm{~W} \mathrm{~m}^{-2}\right)$, the net surface buoyancy flux $B_{0}$ ( $\mathrm{W} \mathrm{kg}^{-1}$ ), and the surface wind stress $\tau_{0}\left(\mathrm{~N} \mathrm{~m}^{-2}\right)$ (Fig. 2). The calculations of $Q_{0}$ and $\tau_{0}$ were performed with the MATLAB Air-Sea toolbox (version 2.0, http://sea-mat.whoi.edu), which employs a simplified version of the Fairall et al. (1996) TOGA/COARE code. The calculation of the net surface buoyancy flux $\left(B_{0}=B_{\mathrm{t}}+B_{\mathrm{s}}\right)$ was obtained from the thermal buoyancy flux $\left(B_{\mathrm{t}}=g \alpha Q_{0} /\left(\rho_{\mathrm{s}} C_{p \mathrm{w}}\right)\right.$, with $\alpha$ the thermal coefficient of expansion of seawater, $\rho_{\mathrm{s}}$ the water density at atmospheric pressure, $C_{p \mathrm{w}}$ the specific heat capacity of seawater) and the haline buoyancy flux $\left(B_{\mathrm{S}}=g \beta(E-P) S_{0}\right.$, with $\beta$ is the coefficient of haline contraction of seawater, $S_{0}$ the surface salinity, and $E-P$ the difference between the evaporation rate and the precipitation rate).

During the cruise, the net surface heat flux was directed from the atmosphere to the ocean at most of the SCAMP 
casts (Fig. 2a). The related net surface buoyancy fluxes ranged from $-5.5 \times 10^{-7}$ to $3.7 \times 10^{-8} \mathrm{~W} \mathrm{~kg}^{-1}$ (Fig. 2b). Note that in this paper we define the heat fluxes (and net surface buoyancy fluxes $B_{0}$ ) as negative when directed downwards (from the atmosphere to the ocean), and thus $B_{0}<0$ indicates a buoyancy flux stabilizing the ocean. The meteorological quantities indicate more negative surface buoyancy fluxes at the southern stations, while surface buoyancy fluxes only slightly stabilize the upper ocean at the northern stations (Fig. 2b). Destabilizing net surface buoyancy fluxes, and consequently possible convectively-driven turbulence, only occurred at station 23 , with only 2 casts and nearly no valid post-processed data due to adverse hydrodynamic conditions when sampling. The surface wind stress ranged from 0.0 to $0.4 \mathrm{~N} \mathrm{~m}^{-2}$ (Fig. 2c) and was derived from wind speeds that ranged from 1.0 to $13.5 \mathrm{~m} \mathrm{~s}^{-1}$ at $10 \mathrm{~m}$ height (Fig. SM2 in the Supplement).

An additional meteorological-related quantity, the MoninObukhov length (LMO, m), was computed for each cast of the cruise as $\mathrm{LMO}=-u_{*}^{3} /\left(\kappa B_{0}\right)$, where $u_{*}=\left(\tau_{0} / \rho_{\mathrm{S}}\right)^{1 / 2}$ $\left(\mathrm{m} \mathrm{s}^{-1}\right)$ is the surface friction velocity and $\kappa=0.4$ is the von Kármán constant. Along the transect, nearly all the stations presented $\mathrm{LMO}>0$ (note that $B_{0}<0$ ), indicating that the mechanically (wind) generated turbulence was being suppressed by the stable stratification. The diurnal mean mixed layer depth (MLD), an indication of the depth through which surface waters have been vigorously mixed within the preceding daily cycle, was computed for each profile as the depth at which the temperature difference with respect to the temperature value at $10 \mathrm{~m}$ depth is $0.2^{\circ} \mathrm{C}$ (de Boyer Montégut et al., 2004). LMOs were generally lower than the respective MLDs, indicating that the wind-induced mixing at the time of sampling could not explain the turbulence over the total depth of the mixed layer (Fig. 2d).

\section{Determination of turbulence quantities}

The strength of the background stratification in the water column has been quantified with the buoyancy (Brunt-Väisälä) frequency, $N\left(\mathrm{rad} \mathrm{s}^{-1}\right)$, which follows from:

$N=\sqrt{-\frac{g}{\rho_{0}} \frac{\partial \bar{\rho}}{\partial z}}$,

where $g\left(\mathrm{~m} \mathrm{~s}^{-2}\right)$ is the gravitational acceleration, $\rho\left(\mathrm{kg} \mathrm{m}^{-3}\right)$ is the water density with the overbar indicating a trimmedsmoothed-sharpened-filtered and binned quantity, $\rho_{0}$ is a reference density, and $z$ indicates the vertical coordinate (positive upward) in m. Details on the computation of $\partial \bar{\rho} / \partial z$ are presented in Appendix A.

Key turbulence quantities for phytoplankton dynamics are the temperature eddy diffusivity, $K_{T}$, and the turbulent kinetic energy dissipation rate, $\varepsilon$. The values of $K_{T}\left(\mathrm{~m}^{2} \mathrm{~s}^{-1}\right)$ have been determined from the temperature microstructure measurements using the Osborn and Cox (1972) model. Assumptions in the Osborn and Cox (1972) model include a stationary balance of the variance of temperature fluctuations, homogeneous and isotropic turbulence, dominance of the vertical heat fluxes over horizontal ones, and the omission of the divergence of the transport terms by the mean flow. $K_{T}$ has been computed from the temperature variance dissipation rate, $\chi_{T}\left({ }^{\circ} \mathrm{C}^{2} \mathrm{~s}^{-1}\right)$, according to

$K_{T}=\frac{\chi_{T}}{2}\left(\frac{\partial \bar{T}}{\partial z}\right)^{-2}$ with $\quad \chi_{T}=6 D_{T} \overline{\left(\frac{\partial T^{\prime}}{\partial z}\right)^{2}}$,

where $D_{T}$ is the molecular diffusivity of heat $(\approx 1.4 \times$ $\left.10^{-7} \mathrm{~m}^{2} \mathrm{~s}^{-1}\right)$. The determination of the vertical gradient of the post-processed temperature, $\partial \bar{T} / \partial z$, and the determination of the post-processed temperature fluctuations gradient, $\overline{\partial T^{\prime} / \partial z}$, and the related uncertainty are described in Appendix A. It should be noted that both $K_{T}$ and $\chi_{T}$, as derived from Eq. (2), are 1-m depth-binned quantities.

The values of $\varepsilon\left(\mathrm{m}^{2} \mathrm{~s}^{-1}\right)$ have been estimated by fitting (in each 1-m bin) the theoretical Batchelor (1959) spectrum of the vertical gradient of the temperature fluctuations to the actual spectrum of the vertical gradient of the temperature fluctuations (Oakey, 1982). In particular, the spectrum of the vertical gradient of the temperature fluctuations has been obtained with a fast Fourier transform of $\partial T^{\prime} / \partial z$ using a Hamming window. In each segment, the representative $\varepsilon$ has been determined from the corresponding optimal value of the Batchelor wavenumber $\left(k_{\mathrm{B} \text { segment }} \mathrm{cpm}\right)$ :

$\varepsilon_{\text {segment }}=\left(2 \pi k_{\mathrm{B} \text { segment }}\right)^{4} \nu_{\text {segment }} D_{T}^{2}$,

where $v_{\text {segment }}\left(\mathrm{m}^{2} \mathrm{~s}^{-1}\right)$ is the arithmetic mean of the molecular kinematic viscosity in the segment.

The fitting to the Batchelor spectrum has been accomplished with the maximum likelihood method developed in Ruddick et al. (2000), which has an explicit incorporation of the instrumental noise, and allows an automated rejection of the segments that poorly fit the spectra. A reliable estimation of the Batchelor wavenumber $k_{\mathrm{B}}$ is critical because of the sensitivity of $\varepsilon$ to $k_{\mathrm{B}}$ according to Eq. (3). The Batchelor fitting is endorsed by the pioneering studies by Dillon and Caldwell (1980) and Oakey (1982), who concluded that $\varepsilon$ determined indirectly through Batchelor fitting agrees within a factor of 2 with the $\varepsilon$ determined from records of velocity shear. The more recent study performed in a lake by Kocsis et al. (1999) leads to similar conclusions. Nash and Moum (2002) slightly favour the theoretical temperature spectrum proposed by Kraichnan (1968) over the Batchelor (1959) spectrum. However, the physics are clearer in Batchelor's model than in Kraichnan's semi-empirical model, and we used the former as the basis for estimating $\varepsilon$. Besides, the fitting algorithm used in this work has been developed for the Batchelor spectrum and for data of SCAMP (Ruddick et al., 2000); hence, fitting to another spectrum would lead to 


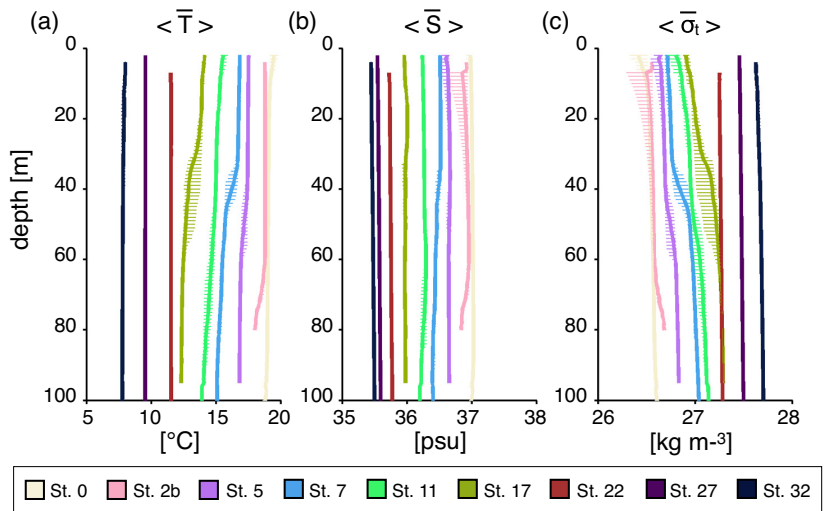

Fig. 3. Depth-binned and station-averaged profiles of (a) temperature $T$, (b) salinity $S$, and (c) sigma-t $\sigma_{\mathrm{t}}$ (density $\left.\rho-1000\right)$ at 9 selected stations. The ranges of minimum and maximum values around the station-average are also shown as horizontal bars. The overbar indicates a trimmed-smoothed-sharpened-filtered and binned quantity, and the angle brackets indicate a station-average.

an increase in uncertainty due to the lack of clear rejection criteria.

The MATLAB routines used to compute these turbulence quantities were partly based on the processing software provided by PME with the SCAMP system, version 1.09.

\section{Results}

\subsection{Measured hydrographic properties}

Temperature, salinity, and density profiles follow the expected variation from a warmer and saltier water column in the south to a colder and fresher water column in the north (Fig. 3). The values are within the range of those measured in the northeast Atlantic (Pollard and Pu, 1985; van Aken, 2001), and the potential temperature-salinity relation indicates water masses belonging to the Eastern North Atlantic Central Water (ENACW). The profiles are fairly constant with depth, since the signature of winter deep convective mixing events is still present at the time of sampling. The salinity profiles are more uniform than those of temperature, and thus do not favour stable density stratification, if existent, in the same way that the temperature profiles do.

In the first half of the cruise, stations 0 to $17\left(29^{\circ} \mathrm{N}-\right.$ $46^{\circ} \mathrm{N}$ ), the stations have thermoclines ranging from $19 \mathrm{~m}$ to $67 \mathrm{~m}$ (Fig. 3). These observations are consistent with common features in the subtropical Atlantic, where only the upper $75 \mathrm{~m}$ tend to be affected by the annual cycle, while the layers below $75 \mathrm{~m}$ remain stably stratified throughout the year (van Aken, 2001). In the second half of the cruise, stations 22 to $32\left(53^{\circ} \mathrm{N}-63^{\circ} \mathrm{N}\right)$, the upper $100 \mathrm{~m}$ are well mixed, resulting in vertically uniform temperature, salinity, and density profiles (Fig. 3). These observations agree with the tendency of high latitudes in the Atlantic to have the up- per $200 \mathrm{~m}$ well mixed from December to April (van Aken, 2001). The change from thermoclines at $50 \mathrm{~m}$ to thermoclines well below $100 \mathrm{~m}$ occurs at around $48^{\circ} \mathrm{N}$ (CTD station 19). This rapid change agrees with the increase of convective winter mixing from $200 \mathrm{~m}$ to $500 \mathrm{~m}$ at $\sim 46^{\circ} \mathrm{N}$ in the northeast Atlantic as reported elsewhere (Pollard and Pu, 1985; van Aken, 2001). At most of the stations in the first half of the cruise, the measured thermocline was not in the same position during the profiling time, the temperature profiles presented small steps, and the computed MLD was not always well defined from the temperature profiles (low quality index in Lorbacher et al. (2006)). These may be indications of the beginning of the building of the seasonal thermocline which will be at its shallowest point in summer.

Figure 4 shows the squared buoyancy frequency along the transect, with the bins with static instabilities $\left(N^{2}<0\right)$ marked in grey. The values of buoyancy frequency are low and indicate a weak stratification in the whole cruise, especially in the northern stations. Larger values occur just below the MLD, and also close to the surface, where the daily heating stratifies the upper levels of the water column. At $\sim 80 \mathrm{~m}$ depth at the stations of the first half of the cruise, the buoyancy frequency increases slightly; it is a sign of the existence of permanently stratified waters below $80 \mathrm{~m}$. The bins with static instabilities, adding up to a $23 \%$ of the total number of bins of the cruise, indicate an important source of turbulence in all the stations of the cruise. In the bins with static instabilities, the release of potential energy occurs through the descent of a plume of denser water and the ascent of a plume of lighter water. The average relative standard deviation due to bin-averaging, $\mathrm{RSD}_{\text {bin }}$, of the $N$ values depicted in Fig. 4 is about $49 \%$, with higher values located close to the surface and in the thermocline (we refer to Appendix A for details about the computation of $\mathrm{RSD}_{\mathrm{bin}}$ ).

\subsection{Derived turbulence quantities}

The values of temperature eddy diffusivities, $K_{T}$, and turbulent kinetic energy dissipation rates, $\varepsilon$, are in the upper range of reported turbulence levels in the upper ocean, and are representative of daytime early spring upper ocean waters. $K_{T}$ values range from $10^{-5}$ to $2 \times 10^{0} \mathrm{~m}^{2} \mathrm{~s}^{-1}$ (Fig. 5) and $\varepsilon$ values range from $3 \times 10^{-8}$ to $10^{-5} \mathrm{~m}^{2} \mathrm{~s}^{-3}$ (Fig. 6). These turbulence quantities are, on average, one order of magnitude higher than those measured in summer, along about the same transect, and with a comparable atmospheric forcing (JDW12). The TKE dissipation rates within the mixed layer are somewhat lower than those reported for the North Atlantic in Lozovatsky et al. (2005), referring to April 2001, and to atmospheric conditions favouring additional convective mixing. The uncertainty of the turbulence quantities, expressed by the relative standard deviation $\mathrm{RSD}_{\text {bin }}$ (see Appendix A) ranges from $\sim 30 \%$ to $400 \%$ for $K_{T}$, and from $\sim 2 \%$ to $100 \%$ for $\varepsilon$. Peaks of RSD bin of $K_{T}$ occur in the less stratified areas, where the existing small vertical temperature 


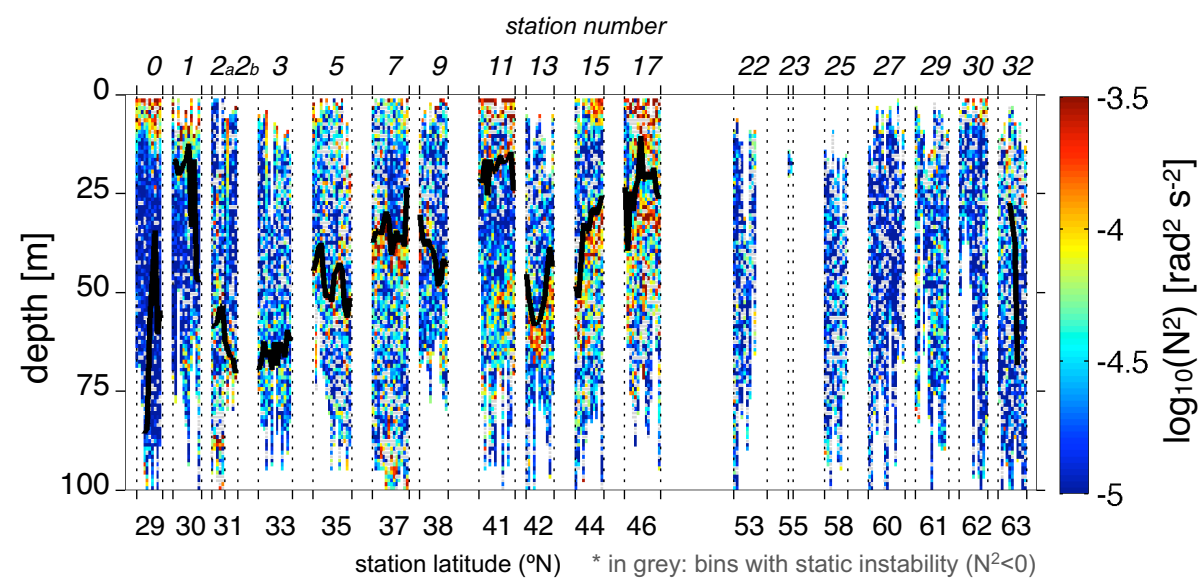

Fig. 4. Depth-binned profiles of the squared buoyancy frequency $N^{2}$, derived from the SCAMP measurements along the transect. Station numbers are labelled on the top axis, and the corresponding latitude is shown on the bottom axis. The mixed layer depth (MLD) for each cast is also plotted as the thick black curve. The plot has a vertical bin resolution of $1 \mathrm{~m}$.

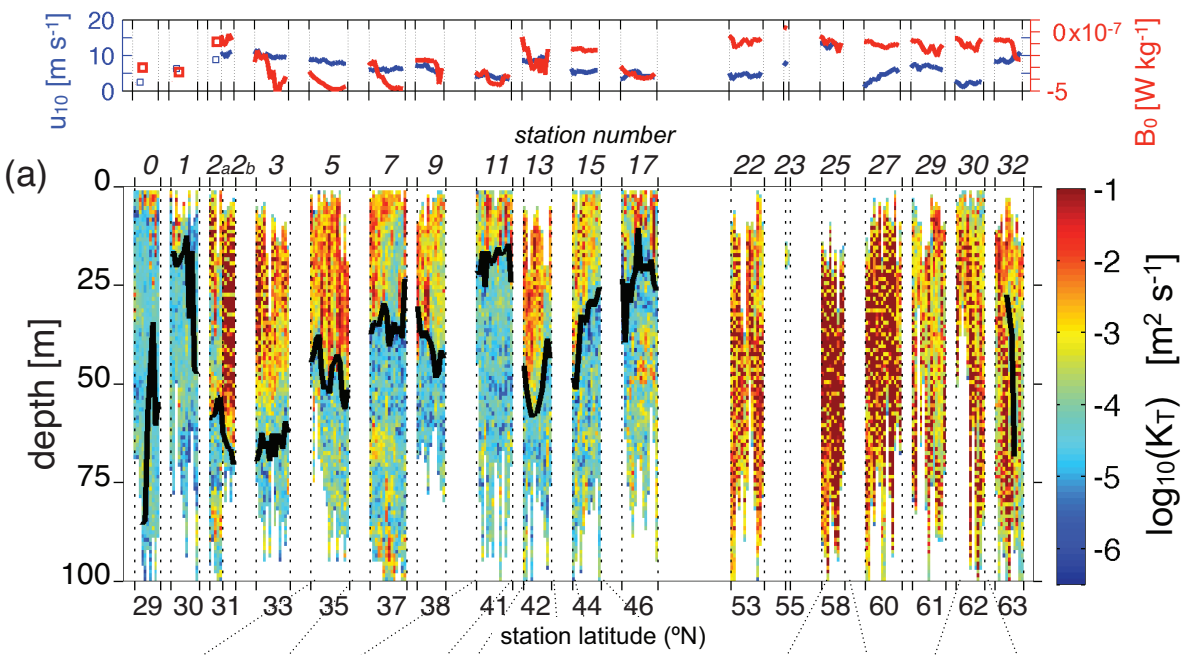

(b)
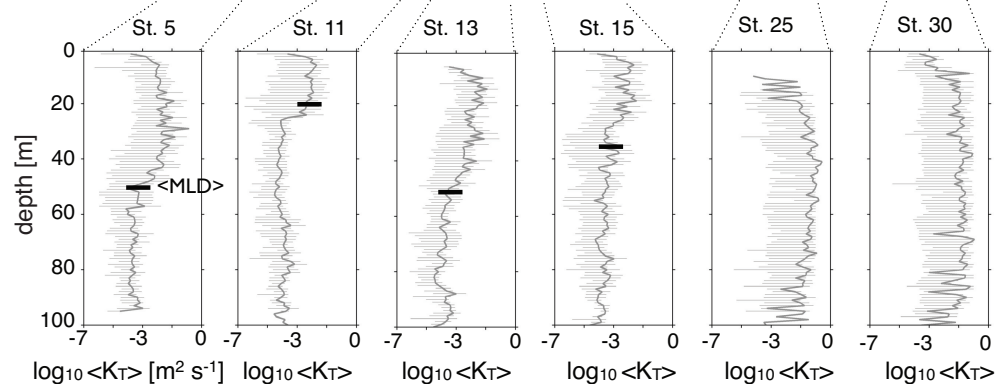

Fig. 5. Depth-binned profiles of temperature eddy diffusivity $K_{T}$ (a), and station-averaged profiles at representative stations (b). The ranges of minimum and maximum values around the station-average are shown in (b). The wind speed at $10 \mathrm{~m}$ height $u_{10}$ and the net surface buoyancy flux $B_{0}$ are depicted in the top panel. Station numbers are labelled on the top axis, and the corresponding latitude is shown on the bottom axis. The mixed layer depth (MLD) for each cast is also plotted as the thick black curve. The angle brackets indicate a station-average.

gradients cause a large uncertainty in $K_{T}$. Peaks of $\mathrm{RSD}_{\text {bin }}$ of $\varepsilon$ tend to occur in the more stratified regions.

The vertical profiles of $K_{T}$ tend to peak around the middle of the mixed layer and decrease both toward the surface (where the proximity of the boundary reduces the size of the turbulent eddies) and toward the bottom of the mixed layer (where the increased water column stability reduces the turbulent mixing) (Fig. 5b). At the weakly-stratified stations, stations 0 to 17 , station-averaged $K_{T}$ range from $10^{-5}$ to $10^{0} \mathrm{~m}^{2} \mathrm{~s}^{-1}$ in the mixed layer, and are more uniform below 

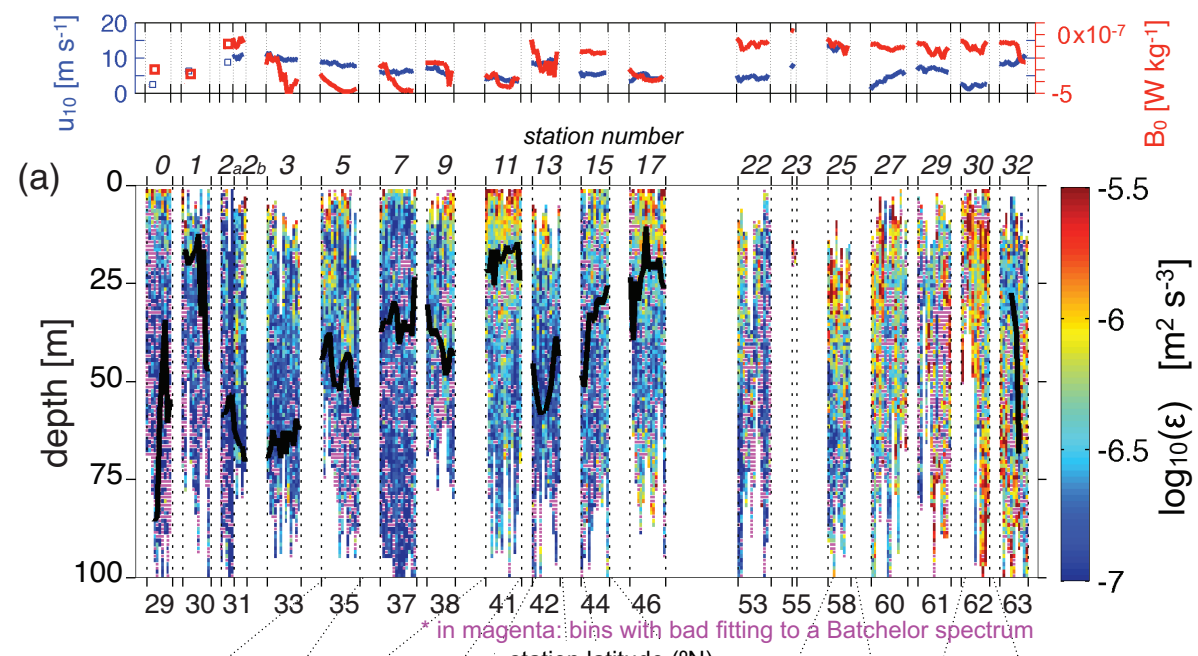

(b)

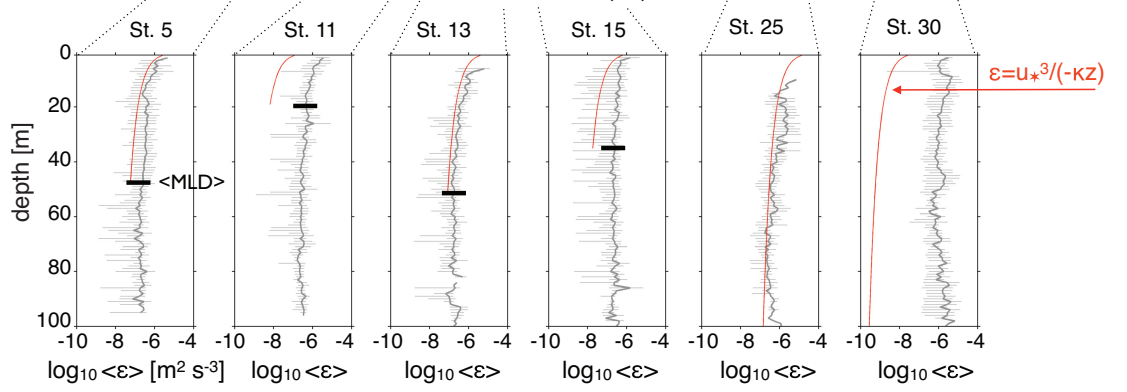

Fig. 6. Depth-binned profiles of TKE dissipation rate $\varepsilon$ (a), and station-averaged profiles at representative stations (b). The ranges of minimum and maximum values around the station-average are shown in (b). We also depict the profiles of $\varepsilon$ as predicted from the wind stress by similarity scaling and a proportionality constant $1\left(\varepsilon=u_{*}^{3} /(-\kappa z)\right)$. The wind speed at $10 \mathrm{~m}$ height, $u_{10}$, and the net surface buoyancy flux, $B_{0}$, are shown in the top panel. Station numbers are labelled on the top axis, and the corresponding latitude is shown on the bottom axis. The mixed layer depth (MLD) for each cast is also plotted as the thick black curve. The angle brackets indicate a station-average.

the mixed layer $\left(\sim 3 \times 10^{-4} \mathrm{~m}^{2} \mathrm{~s}^{-1}\right)$. Further beyond station 22, the vertical profile of $K_{T}$ is more uniform from the surface down to $100 \mathrm{~m}$, reflecting a well-mixed water column, and the station-averaged values range from $3 \times 10^{-4}$ to $2 \times 10^{0} \mathrm{~m}^{2} \mathrm{~s}^{-1}$. Note the significant variability of $K_{T}$ within a station, which can be as large as four orders of magnitude (error bars in Fig. 5b). The related temperature dissipation rates, $\chi_{T}\left({ }^{\circ} \mathrm{C}^{2} \mathrm{~s}^{-1}\right)$, peak in the more stratified regions and are presented in the Supplement (Fig. SM3).

The values of the TKE dissipation rate $\varepsilon$, as expected, show a more uniform vertical distribution than $K_{T}$ (Fig. 6b). Increased values are found close to the surface, from which they tend to decrease exponentially with depth until values of $\sim 10^{-7} \mathrm{~m}^{2} \mathrm{~s}^{-3}$ are reached at $100 \mathrm{~m}$ depth (Fig. 6b). Both weakly-stratified and well-mixed stations present a similar shape in the vertical profile of $\varepsilon$, but well-mixed stations show larger values. A large percentage (around $33 \%$ ) of $\varepsilon$ rejected bins due to a bad fitting to a Batchelor spectrum prevents the calculation of $\varepsilon$ at many locations (Fig. 6a). Segments with a bad Batchelor fitting generally occur at the more stratified regions of the profiles.
A distinctive feature in the data is the latitudinal change of the turbulence quantities, with $K_{T}$ and $\varepsilon$ having larger values in the northern stations (Fig. 7). A similar conclusion was obtained in the STRATIHPYT-I cruise, which was during summer (see JDW12). A more detailed comparison is hard due to the lack of values below the mixed layer in the northern stations, which were the ones that presented a clearer increasing trend towards the high-latitude regions in summer. North of $\sim 48^{\circ} \mathrm{N}$ (CTD station 19), $K_{T}$ values increase significantly and an abrupt change from weakly-stratified water columns to well-mixed water columns occurs. This marks a clear frontier between stations which are permanently stratified in the south and stations which are seasonally stratified in the north. Note that the inter-station tendencies are based on relatively few profiles in each station and meaningful latitudinal trends are difficult to obtain.

\subsection{Atmospheric forcing of the derived turbulence quantities}

Column- and station-averaged values of temperature eddy diffusivity, $K_{T}$, in the mixed layer correlate positively with 


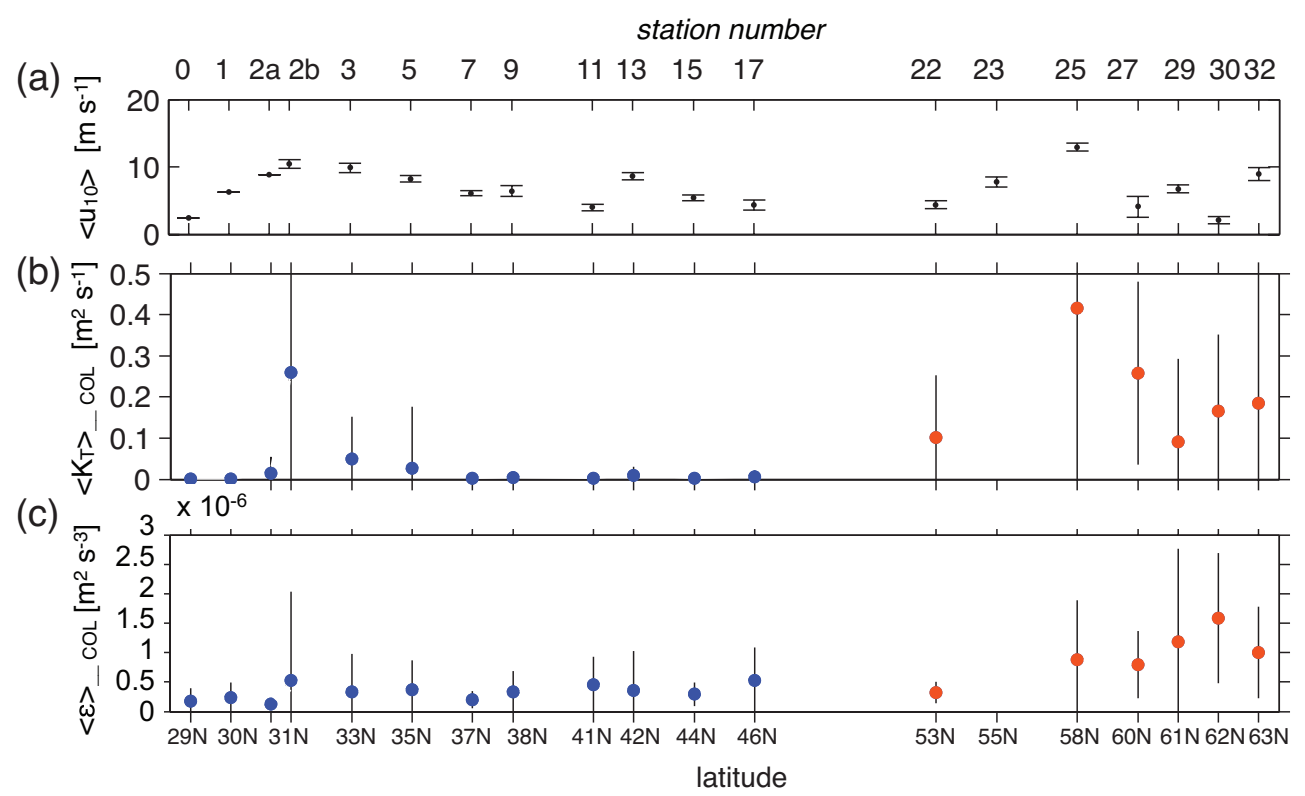

Fig. 7. Station- and column-averaged turbulence quantities, together with the station-averaged wind speeds. Graphs presented for (a) wind speed at $10 \mathrm{~m}$ height $u_{10}$, (b) temperature eddy diffusivity $K_{T}$, and (c) TKE dissipation rate $\varepsilon$. The standard deviation of the stationaveraged wind speeds and turbulence quantities is also depicted. The angle brackets indicate a station-average, and the notation _COL indicates a column-average down to $100 \mathrm{~m}$ depth. The stations south of $48^{\circ} \mathrm{N}$ are depicted in blue filled circles, and the stations north of $48^{\circ} \mathrm{N}$ are depicted in orange filled circles. Note that the station 23 is not shown in (b) and (c) because it had only two profiles.
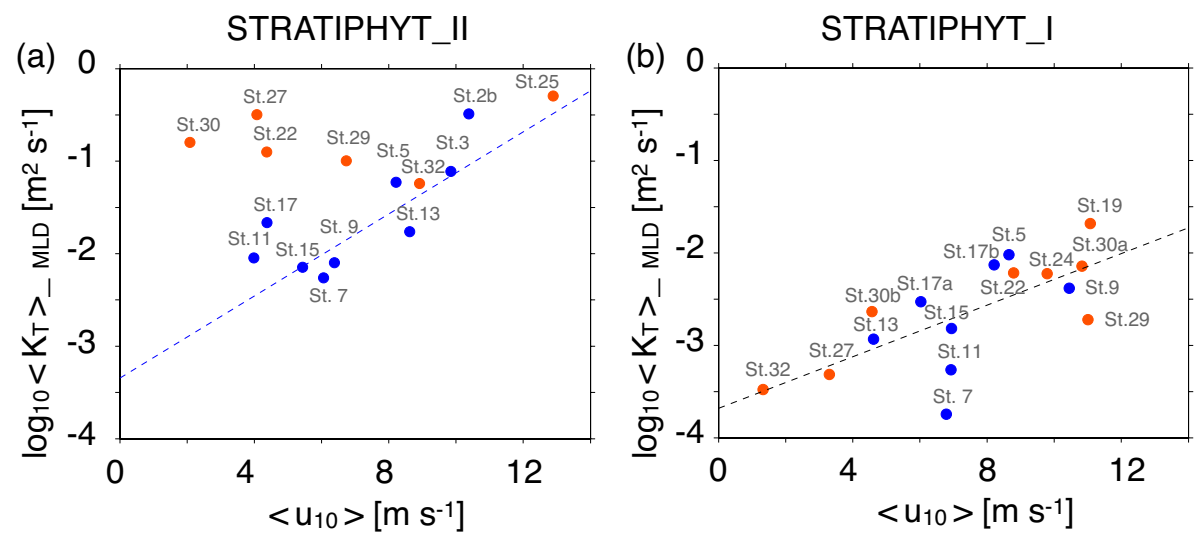

Fig. 8. Station- and column-averaged temperature eddy diffusivity, $K_{T}$, in the mixed layer versus the wind speed at $10 \mathrm{~m}$ height, $u_{10}$. Graphs presented for (a) the STRATIPHYT-II cruise (6 April-3 May 2011), and (b) the STRATIPHYT-I cruise (15 July-9 August 2009 ). The stations south of $48^{\circ} \mathrm{N}$ are depicted in blue filled circles, and the stations north of $48^{\circ} \mathrm{N}$ are depicted in orange filled circles. The angle brackets indicate a station-average, and the notation _MLD indicates a column-average down to the mixed layer depth (MLD). The stations north of $48^{\circ} \mathrm{N}$ in STRATIPHYT-II have larger MLDs than the maximum depth measured by the SCAMP, and at those stations we have performed the column-averages down to $100 \mathrm{~m}$. In (a) we depict the best linear least squares fit for the stations south of $48^{\circ} \mathrm{N}$ $\left(\log _{10}\left\langle K_{T}\right\rangle_{\text {MLD }}=0.22\left\langle u_{10}\right\rangle-3.34\right)$ (if we consider all the stations of the cruise, the correlation between $\left\langle K_{T}\right\rangle$ and $\left\langle u_{10}\right\rangle$ is not significant). In (b) we depict the best linear least squares fit for all the stations of the cruise $\left(\log _{10}\left\langle K_{T}\right\rangle_{\text {MLD }}=0.14\left\langle u_{10}\right\rangle-3.68\right)$. We have not considered stations with less than 3 profiles, and the stations where the anemometer was not working.

the station-averaged wind speed in the weakly-stratified stations of the cruise (stations 0 to 17 ) (Figs. 7 and $8 \mathrm{a}$ ). The best linear least squares fit follows from $\log _{10}\left\langle K_{T}\right\rangle_{-\mathrm{MLD}}=$ $0.22\left\langle u_{10}\right\rangle-3.34$ with a Pearson's correlation coefficient of $0.8\left(\langle\rangle\right.$ indicates a station-average, ${ }_{\text {MLD indicates the }}$ column-average from $1 \mathrm{~m}$ to the MLD, with both the stationand the column-average obtained using the arithmetic mean, and $u_{10}$ is the wind speed at $10 \mathrm{~m}$ height). The slope of the linear regression differs significantly from zero (P-value from the linear regression $t$-test is 0.002 , which is lower 

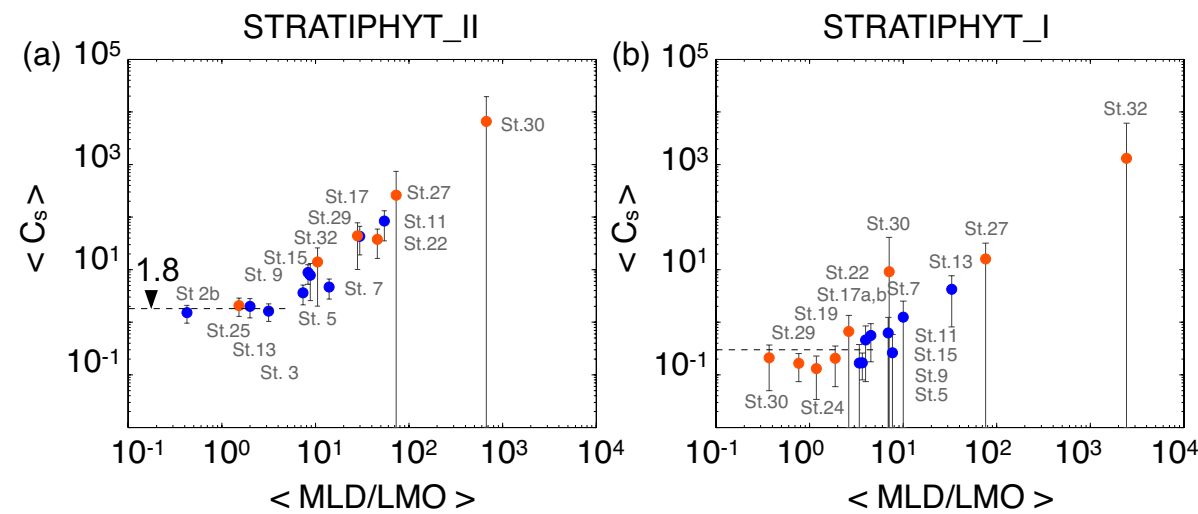

Fig. 9. Station-averaged proportionality constants, $C_{\mathrm{s}}$, that ensure $\varepsilon / \varepsilon_{* \mathrm{~s}}=C_{\mathrm{s}}$ throughout the mixed layer and avoiding the first $5 \mathrm{~m}$ close to the surface because of possible surface wave breaking contamination. Graphs presented for (a) the STRATIPHYT-II cruise (6 April3 May 2011), and (b) the STRATIPHYT-I cruise (15 July-9 August 2009). $\varepsilon$ is the TKE dissipation rate, and $\varepsilon_{* s}$ the related wind stress similarity variable, defined in Eq. (4). The horizontal axis depicts the station-averaged ratio of the mixed layer depth and the Monin-Obukhov length, MLD/LMO. The angle brackets indicate a station-average, and the error bars indicate the standard deviation of the depicted value. The numbering of the corresponding station is also indicated. The stations south of $48^{\circ} \mathrm{N}$ are depicted in blue filled circles, the stations north of $48^{\circ} \mathrm{N}$ are depicted in orange filled circles. The stations north of $48^{\circ} \mathrm{N}$ in STRATIPHYT-II have larger MLDs than the maximum depth measured by the SCAMP, and at those stations we have performed the station-averaged $C_{\mathrm{S}}$ down to $100 \mathrm{~m}$ and we have assumed that MLD is $300 \mathrm{~m}$ to represent $\langle\mathrm{MLD} / \mathrm{LMO}\rangle$. We have not considered stations with less than 3 profiles or the stations where the anemometer was not working.

than the significance level of 0.05). In the well-mixed stations (stations 22 to 32 ), the column- and station-averaged values of $K_{T}$ do not follow a significant positive correlation with the wind speed (Fig. 8a). A more energetic ocean in the northern stations, with MLDs larger than the maximum depth measured by the SCAMP, may contribute to the lack of correlation between the column-averaged $\left\langle K_{T}\right\rangle$ and $\left\langle u_{10}\right\rangle$. The measurements done in the July 2009 cruise (JDW12) follow a similar correlation of $K_{T}$ with $u_{10}\left(\log _{10}\left\langle K_{T}\right\rangle_{\mathrm{MLD}}=\right.$ $0.14\left\langle u_{10}\right\rangle-3.68$ with a Pearson's correlation coefficient of 0.7 and P-value 0.001) (Fig. 8b). Unlike the measurements presented here, in JDW12 all the stations of the first and the second half of the cruise showed a correlation between $\left\langle K_{T}\right\rangle_{\text {MLD }}$ and $\left\langle u_{10}\right\rangle$, in particular at stations with a strong stratification. The correlation of $K_{T}$ to $u_{10}$ agrees with the expected correlation of $K_{T}$ to the MLD (Large et al., 1994), because $u_{10}$ is correlated with the MLD (Fig. 5, Lozovatsky et al., 2005).

Unlike $K_{T}$, column- and station-averaged values of TKE dissipation rates, $\varepsilon$, in the mixed layer do not have a direct positive correlation with the wind speed (Fig. 7). TKE dissipation rates do not appear to respond as quickly as $K_{T}$ to instantaneous wind stress forcing. Based upon similarity scaling and in analogy with atmospheric studies (Monin and Obukhov, 1954), the wind stress-scaled TKE dissipation rate, $\varepsilon / \varepsilon_{* \mathrm{~s}}$, is a non-dimensional parameter and should be a universal function of the scaled depth $-z /$ MLD in the winddominated stations. The energy dissipation rate wind stress similarity variable, $\varepsilon_{* s}$, follows from:

$\varepsilon_{* \mathrm{~s}}=u_{*}^{3} /(-\kappa z)$
Here $z$ is defined positive upward, with $z=0$ at the sea surface, $\kappa$ is again the von Kármán constant, and $u_{*}$ is again the surface friction velocity. Note that we have not assessed the scaling of $\varepsilon$ with the related convective similarity variable because in our study we did not have any profile with TKE production dominated by convection (all the casts had downward net surface buoyancy fluxes).

The proportionality constants determined in the relation $\varepsilon / \varepsilon_{s *}$ during the STRATIPHYT-II cruise are $\sim 1.8$ for stations with wind-dominated mixed layers (low $\langle$ MLD/LMO $\rangle$ in Fig. 9a), and are $\gg 1.8$ for stations with high $\langle\mathrm{MLD} / \mathrm{LMO}\rangle$. The computation of the proportionality constant has been accomplished by averaging $\varepsilon / \varepsilon_{S *}$ throughout the mixed layer and avoiding the first $5 \mathrm{~m}$ close to the surface because of surface wave breaking contamination. For the stations where the Monin-Obukhov depth is shallow compared to the mixed layer depth, the proportionality constants were higher (large $\langle\mathrm{MLD} / \mathrm{LMO}\rangle$ in Fig. 9a). The strength of the stabilizing surface buoyancy flux plays a role since it tends to diminish the LMO and to increase the proportionality constant. A large proportionality constant artificially increases the effect of wind stress in order to account for the "missing" processes of turbulence generation in a simple parameterization Eq. (4).

The proportionality constant (1.8) found for the most wind-dominated stations (stations $2 b, 3,13,25$ ) is somewhat higher than 1 , which is the commonly reported value in conditions of dominant wind stress forcing (Oakey and Elliott, 1982; Soloviev et al., 1988). The proportionality constant found for the less wind-dominated stations (high 
$\langle\mathrm{MLD} / \mathrm{LMO}\rangle)$, is $\gg 1$, agreeing with turbulence microstructure studies (Lombardo and Gregg, 1989). The estimated proportionality constants in STRATIPHYT-II are around 10 times higher than those measured in STRATIPHYT-I in summer under comparable atmospheric conditions (Fig. 9b). In addition, compared to the STRATIPHYT-I cruise, the STRATIPHYT-II cruise presents larger proportionality constants in the second half of the cruise. As the surface forcing itself was fairly similar in both cruises, the increased proportionality constant can only be attributed to past winter convective events, which contribute to higher TKE dissipation rates in the spring season compared to the summer season.

\section{Summary, discussion and conclusions}

In this study we have presented a novel data set of microstructure measurements in 18 ocean CTD stations from Las Palmas de Gran Canaria $\left(27^{\circ} 55^{\prime} \mathrm{N}, 15^{\circ} 22^{\prime} \mathrm{W}\right)$ to Reykjavik $\left(64^{\circ} 6^{\prime} \mathrm{N}, 21^{\circ} 50^{\prime} \mathrm{W}\right)$ during April 2011. The data was obtained with a commercial free-fall microstructure profiler, deployed continuously from $11 \mathrm{~h}$ to $15 \mathrm{~h}$ in the upper $100 \mathrm{~m}$ of the ocean. The observations provide information on the latitudinal changes of turbulence in the upper layers of the ocean. Results presented here are representative of smallscale turbulence measurements of a subtropical to subpolar transect in the northeast Atlantic in the early spring and at midday.

Depth-binned and station-averaged temperature, salinity, and density profiles show the expected variation from a warmer and saltier water column in the low-latitude stations to a colder and fresher water column in the high-latitude stations. We encounter water with low stratification in the stations south of $48^{\circ} \mathrm{N}$, with mixed layer depths ranging from 20 to $80 \mathrm{~m}$ depth, and well-mixed stations north of $48^{\circ} \mathrm{N}$, with mixed layer depths below $250 \mathrm{~m}$. Therefore, the signature of the strong winter deep convective events is still present north of $48^{\circ} \mathrm{N}$. Measured meteorological parameters indicate a range of wind speeds ranging from 1 to $14 \mathrm{~m} \mathrm{~s}^{-1}$. The analysis of the Monin-Obukhov length indicate mechanically (wind) generated turbulence as the dominant atmospheric forcing.

The derived temperature eddy diffusivities, $K_{T}$, display higher values in the mixed layer $\left(\left\langle K_{T}\right\rangle\right.$ : from $10^{-5}$ to $2 \times 10^{0} \mathrm{~m}^{2} \mathrm{~s}^{-1}$ ) with both a decrease toward the surface and toward the MLD. Below the thermocline, and in the weaklystratified stations (stations 0 to 17 ),$K_{T}$ values tend to be vertically uniform and around $3 \times 10^{-4} \mathrm{~m}^{2} \mathrm{~s}^{-1}$. At those stations, $\log _{10}\left\langle K_{T}\right\rangle_{\text {MLD }}$ increase linearly with $\left\langle u_{10}\right\rangle$. The wellmixed stations (stations 22 to 32 ) display larger values than in the weakly-stratified stations, and have more vertically uniform $K_{T}$ profiles, with station- and column-averages down to $100 \mathrm{~m}$ depth that do not correlate with the wind speed. Vertical trends of $K_{T}$ in the weakly-stratified stations and its correlation with the wind speed compare well to those mea- sured in STRATIPHYT-I (JDW12). Both STRATIPHYT-II and STRATIPHYT-I present larger $K_{T}$ in the high-latitude stations. The $K_{T}$ averaged levels in STRATIPHYT-II, as expected, are larger, since in the spring the ocean is more mixed than in the summer.

The TKE dissipation rates, $\varepsilon$, which have been estimated indirectly from our measured temperature gradient fluctuations, range between $3 \times 10^{-8}$ to $10^{-5} \mathrm{~m}^{2} \mathrm{~s}^{-3}$, with larger values in the high-latitude stations. In the stations with mixed layers dominated by wind mixing, as determined by larger Monin-Obukhov scales compared to the MLD, the TKE dissipation rates scale with the wind stress similarity variable with a scaling factor around $1.8\left(\varepsilon \simeq 1.8 u_{*}^{3} /(-\kappa z)\right)$. This value is about ten times higher than the scaling factor reported in JDW12 (STRATIPHYT-I) for the wind-dominated stations during summer. The high levels of TKE dissipation rates measured in spring, also deviating from the commonly reported scaling factor of 1 , may be explained due to past (winter) convective events.

The results presented here constitute, together with that from STRATIPHYT-I (JDW12), a unique data set giving large spatial and quasi-synoptic coverage of microstructure measurements in the upper ocean during spring and summer. It covers a range of stations going from permanently stratified stations in the subtropical east Atlantic to seasonally stratified conditions in the subpolar east Atlantic. This data set may be valuable in large-scale ocean biochemistry models to improve our present understanding of the effects of changes in stratification to the phytoplankton dynamics.

\section{Appendix A}

\section{Averaging procedure and determination of uncertainty}

Although this appendix is similar to the analysis provided in JDW12, we provide it here for convenience so the reader is aware how the raw data are processed.

Due to the intermittent character of turbulence, a single profile can give misleading results. For that reason, the obtained profiles of turbulence quantities along the cruise are depth-binned and station-averaged. In this work we refer to the hat in $\widehat{m}$ as the operation of trimming-smootheningsharpening and filtering (here referred to as TSSF) on the quantity $m$; the overbar in $\bar{m}$ refers to the operation of trimming-smoothening-sharpening-filtering and also depthbinning on the quantity $m$. The notation \langle\rangle refers to the operation of station-averaging, the notation _MLD refers to the column-average throughout the mixed layer, and the notation _COL refers to the column-average down to $100 \mathrm{~m}$ depth. Station-averages and column-averages are obtained using the arithmetic mean.

Data-binning is performed in segments of $1 \mathrm{~m}$ for all depths. In each segment, the TSSF data values are replaced by the segment central value, which corresponds directly to 
the arithmetic mean in the case of temperature $T$, salinity $S$, and density $\rho$. In particular, the depth-binned values of the buoyancy frequency, $N$, are determined by first estimating the vertical gradient of the mean (background) density, $\partial \bar{\rho} / \partial z$, obtained from the best linear least squares fit in the $1 \mathrm{~m}$ depth bin ( $\sim 700$ scans), using a 40 scans-moving average on the TSSF density versus TSSF depth. In the case of the temperature eddy diffusivity, $K_{T}$, the depth-binned value is related to $\partial \bar{T} / \partial z$, obtained from the best linear least squares fit in the $1-\mathrm{m}$ bin, using a 40 scans-moving average on the TSSF and sorted temperature versus the TSSF depth. In the case of the temperature variance dissipation rate, $\chi_{T}$, the segment central value is related to $\overline{\partial T^{\prime} / \partial t}$, which is obtained from the arithmetic mean of $\widehat{\partial T^{\prime} / \partial t}$. Finally, the TKE dissipation rate, $\varepsilon$, is estimated directly for $1-\mathrm{m}$ segments, and thus depth-binning is not required.

The uncertainty in a depth-binned parameter is quantified through the relative standard deviation, $\mathrm{RSD}_{\text {bin }}(\%)$, of the bin-central value, where $\mathrm{RSD}_{\text {bin }}=100 \sigma_{\text {bin }} / \mu_{\text {bin }}\left(\sigma_{\text {bin }}\right.$ is the standard deviation and $\mu_{\text {bin }}$ the arithmetic mean in the 1-m bin of the TSSF values). The computed $\mathrm{RSD}_{\text {bin }}$ increases slightly with the uncertainty derived from the instrumental error. In particular, the $\mathrm{RSD}_{\text {bin }}$ of $T, C$ and $\rho$ is directly estimated as $100 \sigma_{\text {bin }} / \mu_{\text {bin }}$. The $\mathrm{RSD}_{\text {bin }}$ of $N$ is estimated from the residuals in the least squares procedure to obtain the central value of the bin. In the case of $K_{T}$, $\chi_{T}$ and $\varepsilon$, as $\mathrm{RSD}_{\text {bin }}$ we consider the upper limit resulting from the sum of the uncertainties of the elements in their formulae: $\operatorname{RSD}_{\text {bin }}\left(K_{T}\right)=\operatorname{RSD}_{\text {bin }}\left(\chi_{T}\right)+2 \operatorname{RSD}_{\text {bin }}(\partial \widehat{T} / \partial z)$, $\operatorname{RSD}_{\text {bin }}\left(\chi_{T}\right)=2 \operatorname{RSD}_{\text {bin }}\left(\widehat{\partial T^{\prime} / \partial z}\right) \simeq 2 \operatorname{RSD}_{\text {bin }}(\partial \widehat{T} / \partial z)$, $\operatorname{RSD}_{\text {bin }}(\varepsilon)=4 \mathrm{RSD}_{\text {bin }}\left(k_{\mathrm{B}}\right)$. The depth-binned uncertainty of $\partial \widehat{T} / \partial z$ is computed from the standard deviation and the mean of $\left(T_{\max }-T_{\min }\right) /\left(z_{\max }-z_{\min }\right)$ in a 40 scans-moving average. The depth-binned uncertainty of the Batchelor wavenumber $k_{\mathrm{B}}$ is determined from the goodness of the fit of the theoretical spectrum of the vertical gradient of the temperature fluctuations to the observed spectrum, as described in Ruddick et al. (2000). Additionally, the RSD bin of $K_{T}, \chi_{T}$, and $\varepsilon$ may increase when the uncertainties due to the assumption of a steady homogeneous isotropic turbulence and to the Taylor's (1938) hypothesis of "frozen turbulence" are taken into account.

\section{Supplementary material related to this article is

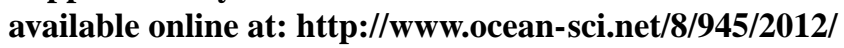 os-8-945-2012-supplement.pdf.}

Acknowledgements. Special thanks go to Corina Brussaard, the chief scientist of the STRATIPHYT-II cruise, and the crew of the R/V Pelagia. We also acknowledge the support of NIOZ-Marine Research Facilities (MRF) on-shore and on-board, and the University of Amsterdam, Jef Huisman, for using their SCAMP. We would also like to thank to A. M. M. ten Doeschate and M. Head for support during the sampling of the data. This work was supported by the Netherlands Organization for Scientific Research (NWO), section Marine and Coastal Research (ZKO), through the STRATIPHYT project.

Edited by: O. Zielinski

\section{References}

Anis, A.: Similarity relationships in the unstable aquatic surface layer, Geophys. Res. Lett., 33, L19609, doi:10.1029/2006GL027268, 2006.

Batchelor, G. K.: Small-scale variation of convected quantities like temperature in a turbulent fluid. Part 1. General discussion and the case of small conductivity, J. Fluid Mech., 5, 113-133, 1959.

Behrenfeld, M., O’Malley, R. T., Siegel, D., and McClain, C. R.: Climate-driven trends in contemporary ocean productivity, $\mathrm{Na}$ ture, 444, 752-755, 2006.

de Boyer Montégut, C., Madec, G., Fischer, A., Lazar, A., and Iudicone, D.: Mixed layer depth over the global ocean: an examination of profile data and a profile-based climatology, J. Geophys. Res., 109, C12003, doi:10.1029/2004JC002378, 2004.

Dillon, T. and Caldwell, D.: The Batchelor spectrum and dissipation in the upper ocean, J. Geophys. Res., 85, 1910-1916, 1980.

Ezer, T.: On the seasonal mixed layer simulated by a basin-scale ocean model and the Mellor-Yamada turbulence scheme, J. Geophys. Res., 105, 16843-16855, 2000.

Fairall, C. W., Bradley, E. F., Rogers, D. P., Edson, J. B., and Young, G. S.: Bulk parameterization of air-sea fluxes for tropical ocean-global atmosphere coupled-ocean atmosphere response experiment, J. Geophys. Res., 101, 3747-3764, 1996.

Ferrari, R. and Polzin, K.: Finescale Structure of the T-S Relation in the Eastern North Atlantic, J. Phys. Oceanogr., 35, 1437-1454, 2005.

Fozdar, F., Parker, G., and Imberger, J.: Matching temperature and conductivity sensor response characteristics, J. Phys. Oceanogr., 15, 1557-1569, 1985.

Gregg, M. C. and Cox, C. S.: Measurements of the oceanic microstructure of temperature and electrical conductivity, Deep Sea Res., 18, 925-934, 1971.

Huisman, J. and Sommeijer, B.: Population dynamics of sinking phytoplankton in light-limited environments: simulation techniques and critical parameters, J. Sea Res., 2, 83-96, 2002.

Imberger, J. and Boashash, B.: Application of the Wigner-Ville distribution to temperature gradient microstructure: a new technique to study small-scale variations, J. Phys. Oceanogr., 16, 19972012, 1986.

Jonas, T., Stips, A., Eugster, W. and Wüest, A.: Observations of a quasi shear-free lacustrine convective boundary layer: Stratification and its implications on turbulence, J. Geophys. Res., 108, 3328, doi:10.1029/2002JC001440, 2003.

Jurado, E., van der Woerd, H. J., and Dijkstra, H. A.: Microstructure measurements along a quasi-meridional transect in the northeastern Atlantic Ocean, J. Geophys. Res., 117, C04016, doi:10.1029/2011JC007137, 2012.

Kocsis, O., Prandke, H., Stips, A., Simons, A., and Wüest, A.: Comparison of dissipation of turbulent kinetic energy determined 
from shear and temperature microstructure, J. Marine Syst., 21, 67-84, 1999.

Kraichnan, R. H.: Small-scale structure of a scalar field convected by turbulence, Phys. Fluids, 11, 945-953, 1968.

Large, W., McWilliams, J., and Doney, S.: Oceanic vertical mixing: A review and a model with a nonlocal boundary layer parameterization, Rev. Geophys., 32, 363-404, 1994.

Levitus, S., Antonov, J., Boyer, T., and Stephens, C.: Warming of the world ocean, Science, 287, 2225-2229, 2000.

Lombardo, C. P. and Gregg, M. C.: Similarity scaling of viscous and thermal dissipation in a convecting surface boundary layer, J. Geophys. Res., 94, 6273-6284, 1989.

Lorbacher, K., Dommenget, D., Niiler, P., and Köhl, A.: Ocean mixed layer depth: A subsurface proxy of oceanatmosphere variability, J. Geophys. Res., 111, C07010, doi:10.1029/2003JC002157, 2006.

Lozovatsky, I., Figueroa, M., and Roget, E.: Observations and scaling of the upper mixed layer in the North Atlantic, J. Geophys. Res., 110, C05013, http://dx.doi.org/10.1029/ 2004JC002708doi:10.1029/2004JC002708, 2005.

Monin, A. S. and Obukhov, A. M.: Basic laws of turbulent mixing in the surface layer of the atmosphere, Tr. Akad. Nauk SSSR Geophiz. Inst., 24, 163-187, 1954.

Mouriño-Carballido, B., Grana, R., Fernández, A., Bode, A., Varela, M., Domínguez, J. F., Escánez, J., de Armas, D., and Marañón, E.: Importance of $\mathrm{N}_{2}$ fixation vs. nitrate diffusion along a latitudinal transect in the Atlantic Ocean, Limnol. Oceanogr., 56, 999-1007, 2011.

Nash, J. D. and Moum, J. N.: Microstructure estimates of turbulent salinity flux and the dissipation spectrum of salinity, J. Phys. Oceanogr., 32, 2312-2333, 2002.

Oakey, N. S.: Determination of the rate of dissipation of turbulent energy from simultaneous temperature and velocity shear microstructure measurements, J. Phys. Oceanogr., 12, 256-271, 1982.

Oakey, N. S. and Elliott, J. A.: Dissipation within the surface mixed layer, J. Phys. Oceanogr., 12, 171-185, 1982.
Osborn, T. R. and Cox, C. S.: Oceanic fine structure, Geophys. Astro. Fluid, 3, 321-345, 1972.

Pollard, R. P. and Pu, S.: Structure and circulation of the Upper Atlantic Ocean northeast of the Azores, Prog. Oceanogr., 14, 443462, 1985.

Ross, O. N.: Particles in motion: How turbulence affects plankton sedimentation from an oceanic mixed layer, Geophys. Res. Lett., 33, L10609, doi:10.1029/2006GL026352, 2006.

Ruddick, B., Anis, A., and Thompson, K.: Maximum likelihood spectral fitting: the Batchelor spectrum, J. Atmos. Ocean. Tech., 17, 1541-1555, 2000.

Sarmiento, J., Hughes, J. T., Stouffer, R., and Manabe, S.: Simulated response of on cycle to anthropogenic climate warming, Nature, 393, 245-249, 1998.

Sharples, J., Moore, C., and Abraham, E.: Internal tide dissipation, mixing, and vertical nitrate flux at the shelf edge of NE New Zealand, J. Geophys. Res., 106, 14069-14081, 2001.

Soloviev, A., Vershinsky, N. V., and Bezverchnii, V. A.: Small-scale turbulence measurements in the thin surface layer of the ocean, Deep-Sea Res., 35, 1859-1874, 1988.

Taylor, G. I.: The spectrum of turbulence, P. R. Soc. London, 164A, 476-490, 1938.

Toggweiler, J. and Russell, J.: Ocean circulation in a warming climate, Nature, 251, 286-288, 2008.

UNESCO: Tenth Report of the Joint Panel on Oceanographic Tables and Standards, UNESCO Technical Papers in Marine Science, 36, 1981.

van Aken, H. M.: The hydrography of the mid-latitude Northeast Atlantic Ocean - Part III: the subducted thermocline water mass, Deep-Sea Res. Pt. I, 48, 237-267, 2001.

Whalen, C. B., Talley, L. D., and Mackinnon, J. A.: Spatial and temporal variability of global ocean mixing inferred from Argo profiles, Geophys. Res. Lett., 39, L18612, doi:10.1029/2012GL053196, 2012. 